\title{
Fantasía y realidad en Aura de Carlos Fuentes
}

\author{
Blanca Merino \\ University of Cambridge
}

Fuentes ha reconocido que un tema central en toda su obra es el enlace del destino humano con el destino histórico (Fuentes 1990). Esta obsesión queda plasmada desde su primera publicación, la colección de cuentos Los dias enmascarados (1954), hasta la última, Constancia y otras novelas para vírgenes, que se publicó apenas en 1990. Sin embargo, no es la precisión histórica ni el mero discurso histórico lo que Fuentes considera importante. Fuentes persigue una dialéctica que le permita a la historia converger con el presente y con el futuro. En La nueva novela hispanoamericana dice:

Hoy [...] la novela es mito, lenguaje y estructura. Y al ser cada uno de esos términos es simultáneamente los otros dos [...]. Pues, como indica Octavio $\mathrm{Paz}$, "poemas y mitos coinciden en transmutar el tiempo en una categoría temporal espacial, en un pasado siempre futuro y siempre dispuesto a ser presente, a presentarse" [...]. Al inventar o recuperar una mitología, la novela se acerca cada vez más a la poesía y a la antropología (1980 20).

A Fuentes le atrae la atemporalidad y la dualidad del mito, el cual, según Claude Lévi-Strauss, simultáneamente explica tanto el pasado como el futuro. Es una doble estructura, enteramente histórica y ahistórica. Es las dos cosas, lo mismo que el lenguaje y diferente de él (189-190). Siendo atemporal, el mito es también eterno. Por lo tanto, Fuentes cree que en un continente con un pasado irresuelto y con un futuro incierto es solamente la perpetuación del presente lo que podría permitir a los latinoamericanos construir su destino. 


\section{Aura}

Aura escapa a todos los límites. ¿Es un cuento, una nouvelle, un cuento largo, una novela corta? Los cuentos y las novelas emplean técnicas narrativas muy distintas e imponen diferentes dificultades al autor. Técnicamente una nouvelle, según Manuel Durán (1973 70), se asemeja más a un cuento porque su longitud es limitada. Esta limitación, sin embargo, no es un problema para Fuentes. Aura es una nouvelle con la capacidad de una novela y lo compacto de un cuento.

Felipe Montero, un joven historiador y maestro, lee un anuncio de trabajo en el periódico, que parece estar dirigido especialmente a él: un joven historiador con conocimientos de francés requerido para trabajo secretarial. "Sólo falta que las letras más negras y llamativas del aviso informen: Felipe Montero [...]. Pero si leyeras eso, sospecharías, lo tomarías a broma" (41). Convencido de que alguien ya ha aceptado la oferta, Montero se despreocupa del anuncio hasta que se lo encuentra de nuevo al día siguiente. La remuneración ha aumentado, la oferta es irresistible. Asombrado de que alguien aún viva en el centro de la ciudad de México, finalmente encuentra la dirección del anuncio, Donceles 815, entre palacios coloniales convertidos en negocios de reparación y pequeños comercios. La puerta de lá casa se abre apenas con un empujón ligero y antes de entrar a la casa echa un último vistazo a la bulliciosa calle. "Antes de entrar miras por última vez sobre tu hombro, frunces el ceño porque la larga fila detenida de camiones y autos, gruñe, pita, suelta el humo insano de prisa" (43). Dentro de la casá percibe una realidad ajena, un mundo más lento. La casa huele a humedad y a putrefacción, y su obscuridad no la hace menos opresiva que el tráfico afuera, al aire libre. No puede ver adónde va, pero una voz le ordena que cuente un determinado número de escalones para llegar al dormitorio de la dueña. La señora Consuelo Llorente actúa como si lo esperase precisamente a él. Examina su francés y le explica que el trabajo consistirá en hacerle algunos arreglos a las memorias de su marido. Montero vacila, no tiene tantas ganas de aceptar la oferta bajo la condición de residir en Donceles. Empieza a negociar cuando, de repente y como si surgiera de la nada, aparece Aura, la sobrina de la señora Llorente: 
Mirus a un lado y la muchacha está allí, esa muchacha que no alcanzas a ver de cuerpo entero porque está tan cerca de ti y su aparición fuc imprevista, sin ningún ruido[...]. Te moverás unos pasos para que la luz de las veladoras no te ciegue. La muchacha mantiene los ojos cerrados, las manos cruzadas sobre un muslo: no te mira. Abre los ojos poco a poco, como si temiera los fulgores de la recámara. Al fin podrás ver esos ojos de mar que fluyen, se hacen como espuma, vuelven a la calma verde, vuelven a inflamarse como una ola: tú los ves y te repites que no es cierto, que son unos hermosos ojos verdes idénticos a todos los ojos verdes que has conocido o podrás conocer. Sin embargo, no te engañas: esos ojos fluyen, se transforman, como si te ofrecieran un paisaje que sólo tú puedes adivinar y desear (17-18)

Montero resuelve enseguida quedarse, planea terminar con el tex to de Llorente tan pronto como sea posible para dedicarse a su propia investigación histórica y no a memorias mal escritas que no incluyen nada que no se haya dicho antes. Sin embargo, cuando procede a la lectura de Llorente, Montero se da cuenta de que el autor de aquellas memorias había sido seducido por la vieja Consuelo de la misma manera que él lo está siendo por la joven Aura. Ansiando saber más, se roba el tercer fajo de folios del cofre de la recámara de Consuelo $y$, al terminar de leerlos, descubre con horror que él es Llorente y no Montero, en la cama con Consuelo y no con Aura. Una vez descifradas, las memorias de Llorente son para Felipe lo que fueron los textos de Melquiades para los Buendía: la historia de lo que fue y de lo que será. Son memorias que se refieren a una época específica de la historia y que por lo tanto aparentan ser lineales. Pero cuando Montero descubre que revive la vida de Llorente, le es evidente, como al Jector, que el tiempo es de hecho circular. Las memorias de Llorente, escritas en primera persona del singular y en tiempo pretérito (como lo es la narración de "Tlactocatzine, del jardín de Flandes"), se contrastan con las del texto mismo de la nouvelle en segunda persona del singular y en tiempo futuro. El tú, que da la impresión de referirse no solamente a Felipe sino también al lector, se proyecta sobre el yo que se refiere al individuo, a Llorente. La dualidad de las voces masculinas, en el pasado y en el futuro, se confronta con una tercera voz, femenina y en tercera persona, la de Consuelo, que es una voz siempre presente, una voz eterna.

Muchas son las fuentes que inspiraron a Aura. Fuentes aprendio de Pierre Menard que "el arte está hecho de comunicación. No de aislamiento, no de pureza, no de originalidad" (Fuentes Entrevista 
1990): "Aura vino al mundo para aumentar la descendencia secular de las brujas. Cinco, por lo menos cinco, fueron las brujas que parieron conscientemente a Aura" (Fuentes 1988 28-45).

Aura, nos dice Fuentes, pertenece a la misma familia mítica de Aspern Papers de Henry James, de Great Expectations de Charles Dickens y de La reina de las espadas de Pushkin. Todas estas historias tienen tres personajes. En todas ellas un joven trata de descubrir el secreto de una vieja -el secreto de la poesía, del amor, de la fortuna-, y en todas ellas el joven es inevitablemente engañado por una muchacha. Todas estas brujas, a su vez, descienden de Michelet y todas ellas tienen un quinto ancestro, Circe, la hechicera de la metamorfosis (Fuentes 1988 39).

La mutua dependencia entre el hombre y la mujer, como la de todos los opuestos, es un tema común de toda experiencia humana, y es inevitablemente exorcizado en la mitología y en la literatura. En Aura hay dos fuentes principales que reproducen esta oposición, pero que, sin embargo, han permanecido relativamente inexploradas por los críticos: la magia y la historia. La primera se origina en La sorcière de Michelet, de la cual se toma el epígrafe. La segunda está basada en los datos históricos del Segundo Imperio a los que se alude a lo largo de la nouvelle. Una declaración más explícita sobre esto se puede ver en la carta, frecuentemente citada, que Fuentes le escribió a Gloria Durán en diciembre de 1968:

Pero si le soy totalmente franco, esa obsesión nació en mí cuando tenía siete años y, después de visitar el castillo de Chapultepec y ver el cuadro de la joven Carlota de Bélgica, encontré en el archivo de Casasola la fotografía de esa misma mujer, ahora vieja, muerta, recostada dentro de un féretro acojinado, tocada con una cofia de niña: la Carlota que murió, loca, en un castillo, el mismo año en que yo nací. Las dos Carlotas: Aura y Consuelo. Quizás Carlota nunca supo que envejecía. Hasta el fin le escribía cartas de amor a Maximiliano. Correspondencia entre fantasmas. Es toda una parte de nuestra historia y de nuestra vida: la historia de lo que no puede morir porque jamás ha vivido (Durán 210-211).

Aura no es solamente el producto de dos mil años de literatura, ni tampoco la hija de un punto particular en la historia. La creación de Aura es análoga a la creación de Aura por Consuelo. Aura fue concebida y dada a luz por Fuentes. Aura es el producto del deseo, y como el deseo, implica una transformación (Fuentes 1988 45), el 
deseo de morir para poder renacer. Aura necesita también ser la negación de los textos sagrados, de la lógica moderna y del pensamiento científico, porque lucha por ser creativa, por poseer una segunda visión.

Aura y Consuelo confrontan a Montero, y el autor de Aura, mediante la voz tú, se empeña en confrontar al lector a partir del primer párrafo: "Lees ese anuncio: una oferta de esa naturaleza no se hace todos los días. Lees y relees el aviso. Parece dirigido a ti, a nadie más" (9).

El tú reta simultáneamente a Montero y al lector, cuando este último se da cuenta de que "Felipe Montero, por supuesto, no eres Tú. Tú eres Tú. Felipe Montero es el autor de Terra Nostra" (Fuentes 1972 45). La oposición entre el tú y el yo, el futuro y el pasado, contra la voz ella que es eterna, se reproduce a lo largo del texto mediante otras oposiciones binarias - la historia y el mito, la ciencia y la magia, la logica y la intuición, lo pasajero y lo eterno, la cultura y la naturaleza, que permanecen asociadlas a las voces masculinas y femeninas. Por lo tanto, la voz Tú se refiere idealmente al lector masculino. Aura sólo puede confrontar al lector femenino en la medida en que se ha distanciado de Consuelo, Aura y Circe, para convertirse en una mujer como Nora Helmer de Et Dukkehjem (La casa de munecas) de Ibsen: una mujer que ha cesado de ser dueña de su cuerpo y mente y que quiere, como un hombre, "divide his mind from his flesh in order to resemble, through his mind, his God, and through his flesh, his Devil" (Fuentes 1988 40).

Con la mente, el hombre se empeña en dominar el tiempo. Mediante la historia, el hombre puede moldear conscientemente el tiempo en un orden cronológico, en una secuencia lineal. En otras palabras, la historia es la racionalización masculina del tiempo. La historia alude claramente al poder masculino, es un símbolo de su control al permitirle decidir qué ha sido importante, qué amerita recordarse.

Esperas el autobús, enciendes un cigarrillo, repites en silencio las fechas que debes memorizar para que esos niños amodorrados te respeten. Tienes que prepararte (10).

Mediante la historia el hombre puede enmascarar su identidad y reordenar las contradicciones inherentes que el mundo moderno ha 
creado. Cuando Montero llega a Donceles, en el corazón de la ciudad de México, se encuentra con una serie de anacronismos - la calle bulliciosa, el autobús repleto de gente donde uno tiene que vigilar su bolsillo, los edificios barrocos, los viejos palacios convertidos ahora en pequeños comercios - escondidos bajo una capa de falsa modernidad. Los números de las casas han sido revisados y cambiados; los nuevos, yuxtapuestos sobre los viejos. El tiempo puede ser racionalizado en números: en fechas, en horas.

La casa de Consuelo está aislada del mundo masculino que rige fuera de ella. Es una casa que lucha por su sobrevivencia en una ciudad que se empeña en destruirla:

Es que nos amurallaron, señor Montero. Han construido alrededor de nosotras, nos han quitado la luz. Han querido obligarme a vender. Muertas, antes. Esta casa está llena de recuerdos para nosotras (27).

La luz y la oscuridad son un juego de oposiciones binarias importantes que refuerzan la separación de ambos mundos. Montero es incapaz de comprender la nueva realidad que se le presenta, todo permanece oscuro, y tiene que admitir: "No veo muy bien" (55). Cuando entra a la casa por primera vez, entiende que está penetrando en un mundo nuevo y aterrador, pero a pesar del prospecto de un futuro abortado en el México moderno y de la posible influencia de una figura cual Circe, no se detiene:

Tocas en vano con esa manija, esa cabeza de perro en cobre, gastada, sin relieves: semejante a la cabeza de un feto canino en los museos de ciencias naturales. Imaginas que el perro te sonríe y sueltas su contacto helado (11).

Montero trata de persuadirse de que puede enfrentarse a unos cuantos meses dentro de una mansión tan extraña. Pronto reunirá suficiente dinero para dedicarse a su investigación, un trabajo comparativo ambicioso que incluirá la historia de todos los descubrimientos del Nuevo Mundo: "Si el precio de tu futura libertad creadora es aceptar las manías de esta anciana, puedes pagarlo sin dificultad" (32).

Todo cambia cuando, una vez en la casa, se enfrenta a un mundo micheletiano, un mundo en un mito eterno detenido en el pasado, un mundo fuera de su comprensión porque es dominado por mujeres que decidirán su futuro. Pronto abandona Montero su propósito original, 
es fútil. No existe una separación del futuro y del pasado que no sea ilusoria. La búsqueda de la complementariedad y el amor hacen a Montero partícipe de una realidad que el mundo moderno ha querido ignorar. Montero será atrapado para siempre, porque este mundo depende tanto de Montero como Montero depende de él.

La casa de Consuelo representa un mundo opuesto e inverso a todos los axiomas científicos e históricos por los que se ha regido Montero. No es un mundo dominado por la cultura, sino un mundo que se rige por las leyes de la naturaleza, del mito y de la imaginación. En suma, un mundo inspirado y controlado por la sorciere. Consuelo es, gracias a un genio propio de la mujer y de su temperamento (Michelet 1), una bruja. Atrae a Montero mediante sus grandes poderes y sólo le revela la verdadera identidad de Aura cuando ya no hay escapatoria. Su control dentro de la casa es absoluto, ella es la "vieja tiránica, loca y enamorada" que describe Paz (1987 597), la mujer capaz de todo por volver a poseer su juventud y su belleza. Consuelo y Aura intrigan a Montero. Como mujeres, son para él "el Enigma [...]. La mujer no es solamente un instrumento de conocimiento, sino el conocimiento mismo. El conocimiento que no poseemos nunca, la suma de nuestra ignorancia: el misterio supremo" (Paz 1947 72).

La casa de Consuelo es el nido donde todos los hombres y todas las mujeres se encuentran. Felipe es Llorente, pero también es todos los hombres que han existido, Consuelo y Aura, todas las mujeres. Felipe está enamorado de Aura, pero ignora que ella sea creación de Consuelo. Siente atracción por una y repulsión por la otra, pero ambas son la misma. "Nature les a fait sorcières", dice Michelet, y también les ha dado la "sublime puissance de la conception solitaire, la parthegénèse" $(1,10)$. Llorente escribe en sus memorias:

La encontré delirante, abrazada a la almoliada. Gritaba: "Sí, sí, sí, he podido: la he encarnado; puedo convocarla, puedo darle vida con mi vida" [...]. "No me detengas [...]; voy hacia mi juventud, mi juventud viene hacía mi" (55).

Consuelo es estéril, por lo tanto no puede esperar recrear al mundo mediante su propia renovación: sólo puede lograr una creación temporal que debe recrearse continuamente mediante el sacrificio y la magia. Por lo tanto, Aura "c'est l'aura, c'est l'air qui gonfle, et rien de plus" (Michelet 98-99). 
La única escapatoria posible de la cultura y de la historia es la profanación y el erotismo, que son los dobles de la imaginación ( $\mathrm{Paz}$ 1987 592-598). La sacralidad de la cultura moderna y la religión, hechas a la imagen del hombre, tienen que ser desplazadas. La noche de su llegada, Consuelo le pide a Montero que la visite poco más tarde para darle el primer manuscrito de las memorias de Llorente, de manera que ponga manos a la obra de inmediato. Al entrar él al cuarto se encuentra con Consuelo oficiando una misa negra:

Ella no te habrá escuchado, porque la descubres hincada ante ese muro de las devociones [...]. Ella levanta los puños y pega al aire sin fucrzas, como si librara una batalla contra las imágenes que, al acercarte, empiezas a distinguir: Cristo, María, San Sebastián, Santa Lucía, el arcángel Miguel, los demonios sonrientes, los únicos sonrientes en esta iconografía del dolor y la cólera: sonrientes porque [...] ensartan los tridentes en la piel de los condenados, les vacían calderones de agua hirviente, violan a las mujeres, se embriagan, gozan de la libertad vedada a los santos [...]. La señora Consuelo, de rodillas, amenaza con los puños, balbucea las palabras que, ya cerca de ella, puedes escuchar: - Llega, Ciudad de Dios, suena, trompeta de Gabriel. ¡Ay, pero cómo tarda en morir el mundo! (26-27).

Eva logra su redención en la misa negra, y por ello "la Femme... est sacerdose, elle est l'autel, elle est l'hostie, dont tout le peuple communie. Au fond, n'est elle Dieu même?" (Michelet 132). La profanación, sin embargo, es mejor lograda a través del amor humano y del erotismo, porque, al involucrar no sólo a la mujer, sino también al hombre, logra un sacrilegio mayor. El erotismo y la evocación de la muerte llaman a una renovación y a una sustitución de lo sagrado "dans cette nouvelle Église, exactement l'envers de l'autre" (Michelet 83 ), porque el erotismo es el producto del deseo:

Aura, de cuclillas sobre la cama, coloca ese objeto contra los muslos cerrados, lo acaricia, te llama con la mano. Acaricia ese trozo de harina delgada, lo quiebra sobre sus muslos, indiferentes a las migajas que ruedan por sus caderas: te ofrece la mitad de la oblea que tú tomas, llevas a la boca al mismo tiempo que ella, deglutes con dificultad: caes sobre el cuerpo desnudo de Aura, sobre sus brazos abiertos, extendidos de un extremo al otro de la cama, igual que el Cristo negro que cuelga del muro con su faldón de seda escarlata, sus rodillas abiertas, su costado herido, su corona de brezos montada sobre la peluca negra, enmarañada, entreverada con lentejuela de plata. Aura se abrirá como un altar (46-47). 
Profanación y erotismo, horror que limita casi con la muerte, llaman hacia la renovación y la comunión. Solamente mediante la muerte se puede lograr la reencarnación: "Hay que morir antes de renacer". La juventud y la reencarnación son producto del amor. La promesa de Felipe a Aura de amarla para siempre es evocada por Consuelo _-"Si me amas, me amarás siempre, dijiste ayer..." (59)_ como el último requisito para volver a traer a Aura. Aura y Consuelo convocan "la juventud", "la vejez", "la vida", "la muerte" (Fuentes 1972 44), y con la ayuda de Felipe también pueden evocar "la eternidad", nombres todos que, como dice Fuentes, son femeninos. La vejez sólo puede terminarse con la muerte, y la juventud está asociada a la vida.

Por lo tanto, el tiempo es circular, o mas bien, espiral, porque cada nueva reencarnación nos regresa a lo perdido, pero no volvemos a empezar desde el principio, sino desde la última muerte. Montero es Llorente, pero con una variante: ha vivido en otro México y en otro tiempo. Montero tiene una visión retrospectiva de Llorente que Llorente no tuvo de sí mismo: "El francés del general Llorente no goza de las excelencias que su mujer le habrá atribuido. Te dices que tú puedes mejorar ese estilo, apretar esa narración difusa de hechos pasados" (28).

Sólo la repetición y la renovación pueden marcar el paso del tiempo. "Las fechas se te confundirán" (32), y "no volverás a mirar tu reloj, ese objeto inservible que mide falsamente un tiempo acordado a la vanidad humana, esas manecillas que marcan tediosamente las largas horas para engañar el verdadero tiempo" (57). Felipe puede juzgar el paso del tiempo mediante la recreación de Aura en las diferentes etapas de la vida de Consuelo. "La niña Aura" (62) que Llorente describe en sus memorias, "elle avait quinze ans lorsque je l'ai connue et, si j'ose le dire, ce sont ses yeux verts qui ont fait ma perdition" (64): Aura "la mujer" (69), la misma del retrato de 1876, "fait pour notre dixieme anniversaire de marriage" (77), y Aura en la última fotografía, la Aura que inevitablemente exigirá una reencarnación:

Verás en la tercera foto a Aura en compañía del viejo, ahora vestido de paisano, sentados ambos en una banca, en un jardín. La foto se ha borrado un poco: Aura no se verá tan joven como en la primera fotografía, pero es ella, es él, es... eres tú (56). 
La reencarnación necesita la muerte y por lo tanto la pérdida de la identidad, el abandono de uno mismo, el olvido. ${ }^{1}$ El día de su llegada, Felipe se reconoce en el espejo del baño, pero las fotografías que se encuentran junto a las memorias de Llorente le revelan que él es otro:

te tocas los pómulos, los ojos, la nariz, como si temieras que una mano invisible te hubiese arrancado la máscara que has llevado durante veintisiete años: esas facciones de goma y cartón que durante un cuarto de siglo han cubierto tu verdadera faz, tu rostro antiguo, el que tuviste antes y habías olvidado. Escondes la cara en la almohada, tratando de impedir que el aire te arranque las facciones que son tuyas, que quieres para ti (57).

El ciclo de nacimiento, juventud, vejez y reencarnación, como tema fundamental en Aura, es, al igual que en los mitos, repetido al nivel estructural de la nouvelle. Al principio, Consuelo le promete a Felipe: "Sí, volverá" (16); después le dice: "Le dije que regresaría [...]. Aura. Mi compañera. Mi sobrina" (17), y al final: "Volverá, Felipe, la traeremos juntos" (60).

El hombre y la cultura, y por lo tanto la sociedad moderna, son estáticas porque, según dice Michelet "les livres copient les livres, les églises copient les églises... Ils n'ont nulle idée de faire une société nouvelle, ni de féconder l'ancienne" (Michelet 28). Es por ello que el hombre tiene que depender de la mujer, porque ella es la única capaz de renovar y recrear la sociedad:

La mujer intriga y sueña; es la madre de la fantasía, de los dioses. Posee la segunda visión, las alas que le permiten volar hacia el in finito del deseo y de la imaginación... Los dioses son como los hombres: nacen y mueren sobre el pecho de una mujer. (Epígrafe)

Pero la dependencia es mutua. Consuelo no puede triunfar sola. Para proporcionar consuelo necesita de su opuesto, el deseo. El deseo y el amor de Felipe son los requisitos para un proceso de creación y recreación continuo, y con cada reencarnación se refuerza la esperanza de una vida y de un amor eternos:

Hundirás tu cabeza, tus ojos abiertos, en el pelo plateado de Consuelo, la mujer que volverá a abrazarte cuando la luna pase, tea tapada por las nubes, los oculte a ambos, se lleve en el aire, por algún tiempo, la memoria de la juventud, la memoria encarnada.

${ }^{1}$ Michelet 148: "Pour vivre, renaître, le seul moyen est mourir". 
- Volverá, Felipe, la traeremos juntos. Deja que recupere fuerzas y la haré regresar... (60).

La oposición entre lo mágico y lo histórico, entre el dominio del hombre y el de la mujer, es también duplicada al nivel de los nombres propios de los personajes. Todos ellos provienen de La sorciere. Consuelo, Saga y Aura son nombres asociados con el mundo mágico y con los poderes de la bruja, que deben contrastarse con los de Llorente y Felipe, los dos hombres que en Aura sucumben a los poderes de Consuelo. En el libro de Michelet, Llorente es un inquisidor francés de la Edad Media. Consuelo triunfa sobre la Inquisición, porque no sólo sobrevive como bruja, sino que además logra seducir a Llorente y reencarnarlo en el joven historiador Felipe. En La sorciere la bruja decapita a una rana y exclama: "Philippe, si je te tenais, je t'en ferais autant!". De la misma manera, en Aura Consuelo desgarra la identidad de Felipe.

Consuelo y Carlota no sólo tienen una cercanía fonética, sino que, mediante ellas, Fuentes ha logrado reunir el arquetipo, la Consuelo de Michelet y el personaje histórico, Carlota, emperatriz de México, de la misma manera que hace converger a los otros dos dobles, Llorente y Felipe, en una misma persona. Como en un mito, la duplicidad contradictoria de personajes aparenta reproducirse ad infinitum mediante la repetición de otras contradicciones a diferentes niveles: lo viejo contra lo joven, la vida contra la muerte, la decrepitud contra la belleza, lo consciente contra lo inconsciente, el pasado contra el presente, lo mítico contra lo histórico.

Consuelo es Carlota en su lecho de muerte, la Carlota cuya fotografía encontró Fuentes en el archivo Casasola: "Te apartarás para que la luz combinada de la plata, la cera y el vidrio dibuje esa cofia de seda que debe recoger un pelo muy blanco y enmarcar un rostro casi infantil de tan viejo" (14). Consuelo es también la Carlota estéril de la que se rumoreaba que buscaba una cura de hierbas medicinales para la infertilidad (55); Aura es Carlota en su juventud, la ambiciosa joven emperatriz de México; Blasio, el joven mexicano secretario de Maximiliano, es también Montero, "capaz de desempeñar labores de secretario. Juventud, conocimiento del francés" (9); Llorente es Maximiliano, que también murió sesenta años antes que su esposa y escribió igualmente sus memorias (16), y Felipe es 
Maximiliano, el emperador que se mantendrá en una juventud eterna porque murió a la edad de treinta y cinco años.

La precisión histórica no es importante porque el objetivo es permitir que todos los tiempos converjan. Consuelo es más vieja de lo que fue Carlota, Llorente ha vivido más allá del Segundo Imperio y se ha convertido en viejo. El Imperio se mantiene durante tres años, Aura sólo puede sobrevivir tres días. La literatura, mediante la fuerza poderosa de la imaginación, puede llenar el vacío que la historia no puede superar. En la historia había dos Carlotas, la joven pintada por Winterhalter y por Graefle y la vieja del archivo Casasola. Había, sin embargo, sólo un Maximiliano, el joven Max que murió heroicamente en el Cerro de las Campanas, el que no tuvo tiempo de convertirse en un monarca tiránico, en un corrupto inquisidor Llorente, o en un mexicano desleal que diera apoyo a una monarquía extranjera en el exilio y la vejez. Ahora pueden existir dos versiones de Maximiliano, Felipe se puede comparar con Aura y con Consuelo en el presente y en el pasado, en la juventud y en la vejez. Felipe, que como historiador e inquisidor estaba lo más alejado de la fantasía, la creación y la imaginación, se verá para siempre confrontado con una segunda vision: es forzado a dejar de ser lo que fue, a empezar de nuevo.

Cosa típica de la erudicion de Fuentes, en Aura hay un enlace adicional que refuerza la complementariedad entre el libro de Michelet y la historia mexicana del Segundo Imperio, más allá de la oposición necesaria entre la magia y la historia que ellos representan. Montero tiene que reescribir las memorias que Llorente-Maximiliano escribió, pero también reencarna a Michelet como un historiador que se ve obligado a escribir, más allá de la verdad de la historia. "La vérité de la légende et de la poésie" (Refort 8). La sorcière fue publicada en 1862, el mismo año en que la intervención francesa hizo posible la instalación de uná monarquía europea en México, haciendo realidad el deseo de Napoleon. Michelet y la princesa belga, Charlotte, fueron contemporáneos.

La creación de Aura que logra Fuentes es análoga a la creación de Aura que logra Consuelo. Consuelo tiene que lidiar con la magia y la brujería. Fuentes con el lenguaje. El lenguaje es la única arma contra la sacralidad de los textos históricos, los cuales, por serlo, están fuera de la realidad. Mediante el lenguaje y la imaginación 
Fuentes puede recrear el pasado y, al hacerlo, busca descubrir la verdadera identidad que se encuentra debajo de la máscara. "La sorcière date [...] des temps du désespoir" (Refort 8), pero, más allá del horror presente, la sorciere y Fuentes intentan dar esperanzas para el futuro, mediante la alegoría de una reencarnación.

Los polos opuestos, la historia y la ficción, la ciudad y Donceles 815 , lo exterior y lo interior, presentan realidades igualmente aterradoras. La falsedad de la historia y de la lógica no causan menos horror que los efectos de la brujería, los sacrificios simbólicos, los estupefacientes y narcóticos de "las plantas de sombra" que encuentra Montero en el jardín, el líquido rojo y espeso que es el vino, los gatos, el conejo. Montero es progresivamente hipnotizado, duda de sus sentidos, confunde el sueño y la vigilia, no comprende nada. Es sólo mediante la reconciliación de ambos mundos como se puede poseer y mantener una esperanza para el futuro.

BIBLIOGRAFÍA CITADA

Durán, Gloria. La magia y las brajas en la obra de Carlos Fuentes. México: UNAM, 1976.

Durán, Manuel. Tríptico mexicano. México: SEP, 1973.

Fuentes, Carlos. Aura. México: Alacena/Era, 1972.

- - Constancia y otras novelas para vírgenes. México: FCE, 1990.

_- . La nueva novela hispanoamericana. México: Joaquín Mortiz, 1980.

- - Los días enmascarados. México: Los Presentes, 1954.

-_ - Myself with others. Londres: Andre Deutsche, 1988.

- - . "The Epic Urbanity of Citizen Carlos." Con Peter Gutridge. The Sunday Times. Books. 25 feb. 1990.

Levi-Straujs, Claude. Antropología estructural. Trad. Eliseo Verón.

Buenos Aires: Edit. Univ. de Buenos Aires, 1968.

Michelet, Jules. La sorcière. París: Marcel Didier, 1952.

Paz, Octavio. El laberinto de la soledad. México: FCE, 1947.

- - . "La máscara y la transparencia." Vol. 2 de Méxicu en la obra de Octavio Paz. Ed. O. Paz y L. M. Schneider. México: FCE, 1987. 592598.

Refort, Lucien. "Introduction. " Jules Michelet. La sorcière. París: Marcel Didier, 1952. 